\title{
CONSIDERATION CONCERNING THE INFLUENCE ON A BREAKWATER IN THE SUPERPOSITION OF EARTHQUAKE AND TSUNAMI
}

\author{
Katsuhiro Okada ${ }^{1}$, Kojiro Suzuki ${ }^{1}$ and Taro Arikawa ${ }^{2}$
}

\begin{abstract}
When a major earthquake occurs, it can be followed by an incoming tsunami, both of which destroy many structures and cause serious damage. Although the destruction of structures caused by earthquakes and by tsunamis has been studied, the further damage caused by aftershocks after a major earthquake occurring at the time of a tsunami has not been sufficiently reported. In this study, we aimed to determine variations in the influence of different structural shapes when the effects of an earthquake and tsunami are superposed. A sloping structure was shown to reduce the hydrodynamic pressure; even when an earthquake and tsunami occur simultaneously.
\end{abstract}

Keywords: breakwater; tsunami; earthquake

\section{INTRODUCTION}

The recent earthquakes in Chile and Japan generated huge tsunamis and many protective facilities were destroyed. Most of the damage was caused by tsunami overflows (Arikawa et al., 2012). Once protective facilities collapse, damage to the hinterland increases, so protective facilities should be designed to withstand tsunamis. Widening work is considered one way to improve resilience. Arikawa et al. (2013) clarified the effect of such widening work, allowing the measure to be implemented in many ports.

A large earthquake may cause a huge tsunami whilst earthquake aftershocks continue. Tsunami overflow can last up to 5-10 minutes, hence the potential for the tsunami overflow to overlap with relatively strong aftershocks. Under these circumstances, the stability of breakwaters is likely to decrease. However, there is a lack of research examining the superposition of the effects of an earthquake and a tsunami, since most research looks at tsunamis and earthquakes separately.

The purpose of this study is to clarify the simultaneous effects of an earthquake and tsunami overflow using physical experiments. The stability of different types of breakwaters and seawalls was investigated using hydraulic model tests, which can generate earthquake motion and tsunami overflow simultaneously.

\section{HYDRAULIC MODEL TEST}

A hydraulic model experiment was conducted in the large hydro geo flume owned by the Port and Airport Research Institute. As an experimental apparatus, a large pump installed as a reflux apparatus was used to generate flow and the overflow condition due to the tsunami was reproduced. The earthquake was reproduced using an underwater shaking table installed at the facility, which can vibrate up to $1.5 \mathrm{G}$. (Fig. 1)

The experiment confirmed the structural impact when superposing the earthquake and tsunami, and the variation due to differing structural shapes where the model was fixed and structural stability for non-fixed models were examined.

In the fixed experiments, three different models were used: a vertical-caisson type breakwater, a sloping top-caisson type breakwater and a coastal dike. The model was fixed to the concrete plate installed on the shaking table and was unaffected by deformation of the model.

In the non-fixed experiment, two different models of vertical-caisson and sloping-top type breakwaters were used to examine differences in stability during the earthquake and tsunami superposition.

The experiments reproduced each overflow state. Once a steady overflow had been confirmed, excitation was performed and the phenomenon of a superimposed earthquake and tsunami was reproduced. In addition to using a wave gauge and current meter, data was measured using a wave pressure gauge, an accelerometer and a displacement meter around the model.

\footnotetext{
${ }^{1}$ Port and Airport Research Institute, Yokosuka, Kanagawa, Japan

${ }^{2}$ Chuo University, Kasuga, Tokyo, Japan
} 


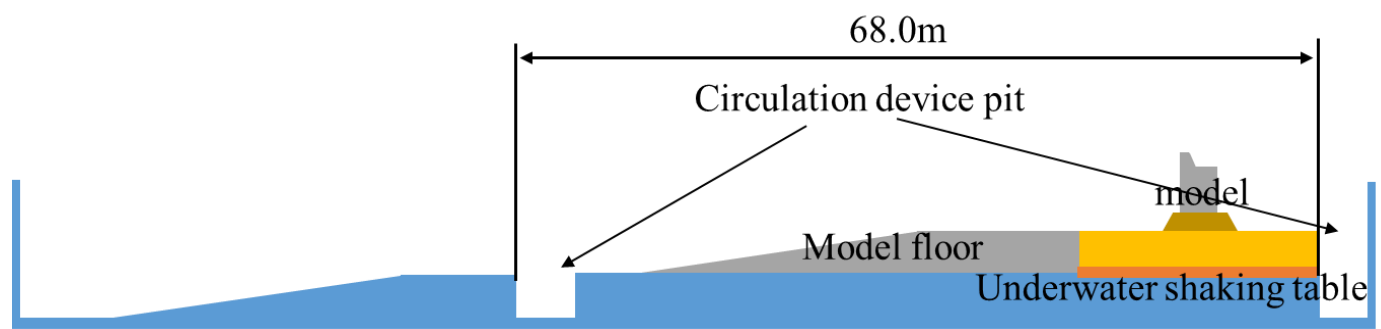

(a) The entire facility

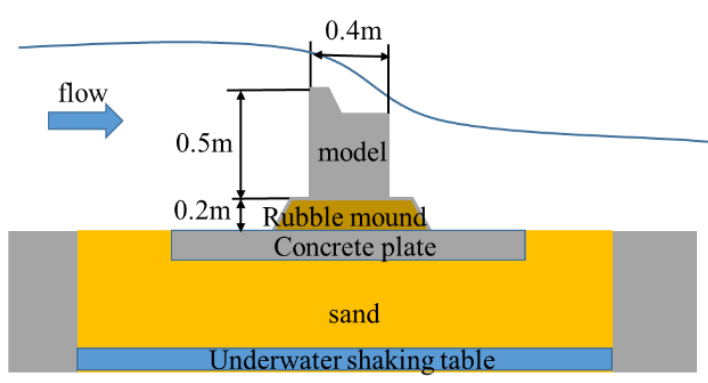

(b) Fixed experiment model

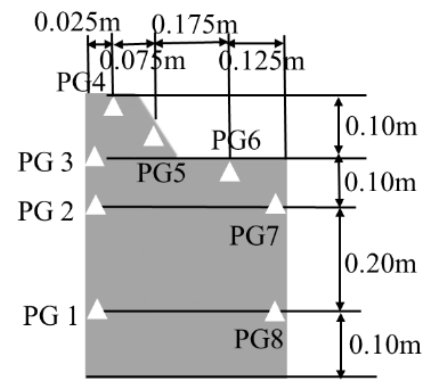

(d) Vertical caisson (fixed model)

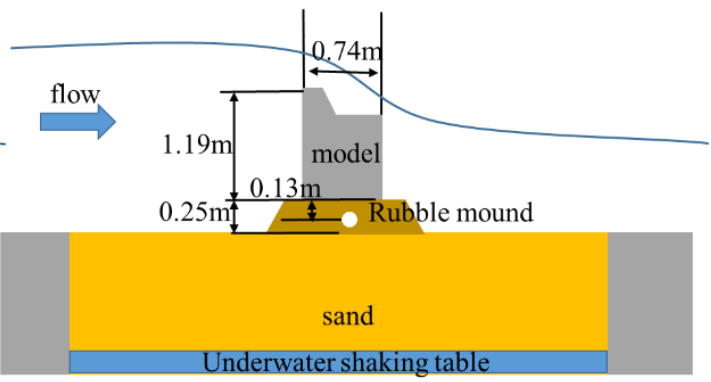

(c) Non-fixed experiment model

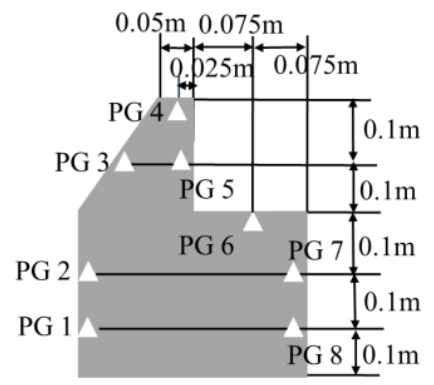

(e) Sloping top caisson (fixed model)

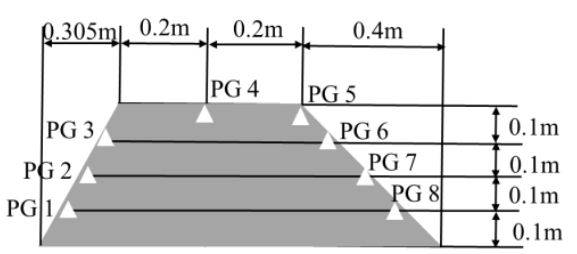

(f) Coastal dike (fixed model)

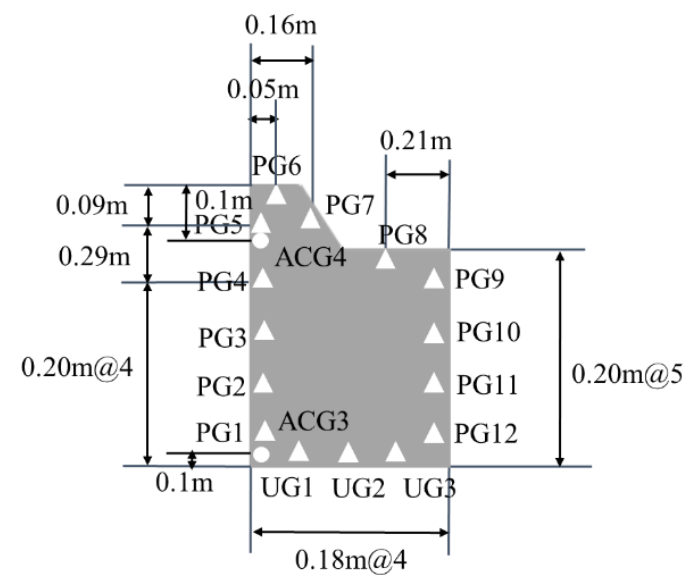

(g) Vertical caisson (non-fixed model)

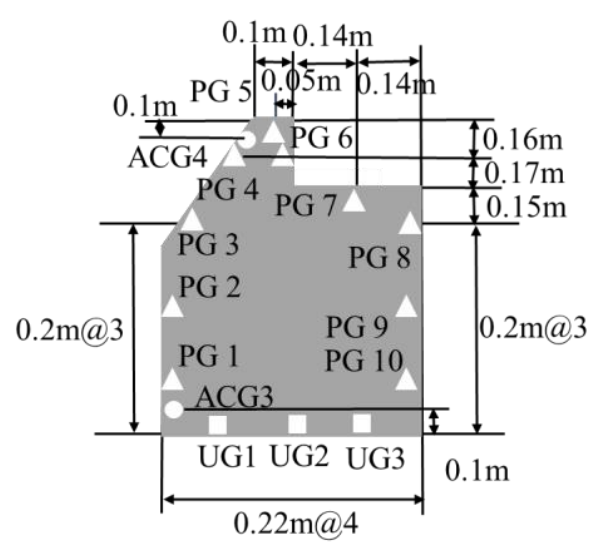

(h) Sloping top caisson (non-fixed model)

Figure 1 Experimental cross-sections 


\section{RESULTS OF THE HYDRAULIC MODEL TESTS}

\section{Difference in hydrodynamic pressure during excitation with or without overflow in a fixed experiment}

The examined models included different types. The experiment involved exposing the material to 50 gal shaking; comparing both the case of shaking only and that of superimposing overflow and shaking.

Comparing the wave pressure in the breakwater with the vertical-caisson type, the wave pressure where the shaking and overflow was superposed was larger in the front of the model than that in the case of the shaking alone. In the rear of the model, conversely, the wave pressure of the case of shaking alone exceeded the case of the shaking and overflow superposed. This is because in the latter case, the water level at the front of the model increases due to the influence of the overflow and the water level at the back of the model declines accordingly and the difference in water level also affects the hydrodynamic pressure. (Fig. 2)

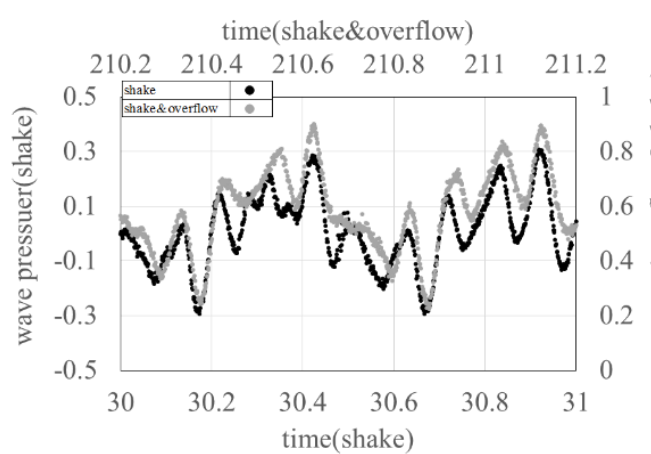

(a) Front

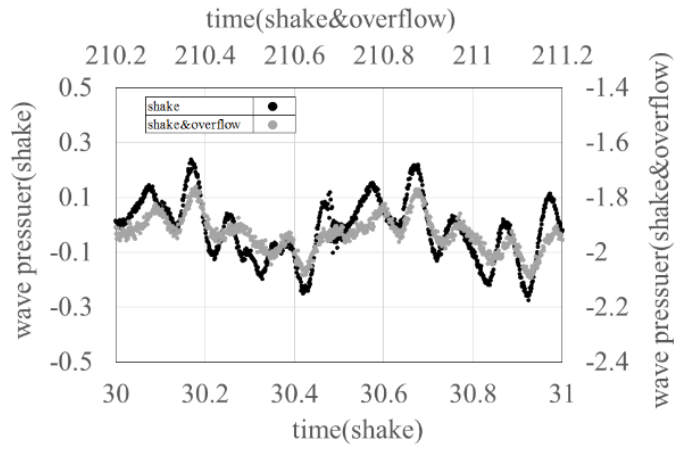

(b) Rear

Figure 2 Wave pressure time history (vertical caisson)

For the sloping top-caisson type, like the breakwaters of the vertical-caisson type, the upright part on the lower side of the model is subject to the impact of water level fluctuation due to the overflow during the shaking and overflow superposition. Conversely, the part on the upper slope of the model front is unaffected by the water level and the hydrodynamic pressure remains virtually constant when superposing the shaking and the shaking and overflow. It is thought that because the structure is not vertical in terms of the vibration direction of shaking, any rise in hydrodynamic pressure was suppressed. In addition, on the rear side of the slope of the upper side of the model, the model is not directly in contact with the water surface due to the influence of the overflow, so the influence is small when superimposing the shaking and overflow. (Fig. 3)

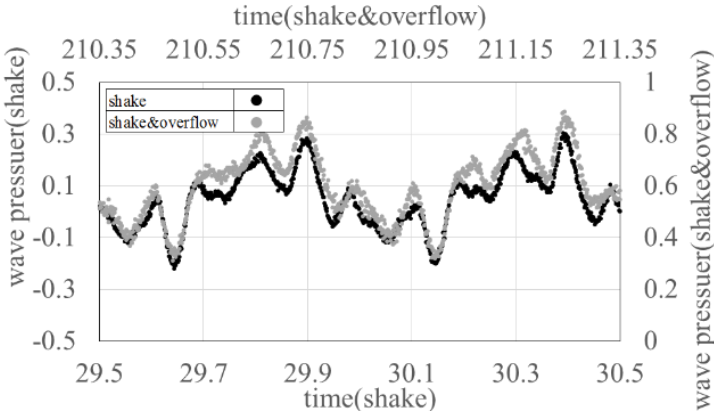

(a) Front

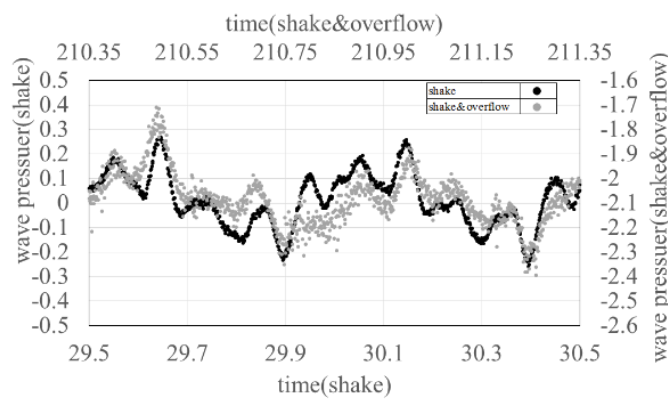

(b) Rear

Figure 3 Wave pressure time history (sloping top caisson)

As for the coastal dike type, on the model front, like the sloping top-caisson type, the hydrodynamic pressure was unaffected by the water level, while the hydrodynamic pressure was almost 
constant when superposing the shaking and the shaking and overflow. On the rear of the model, during the shaking and overflow superposition and due to the influence of the overflow, no large dynamic hydrodynamic motion could be confirmed above the model. Conversely, on the lower side of the model, the wave pressure during the shaking and overflow superposition rose due to the impact of the overflowing water mass. (Fig. 4)

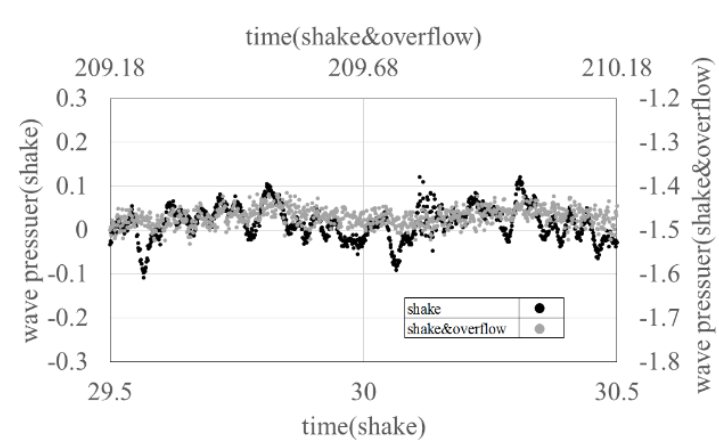

(a) Front

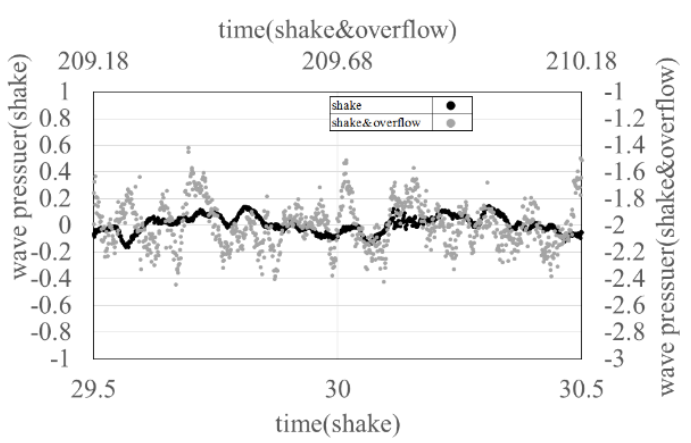

(b) Rear

Figure 4 Wave pressure time history (coastal dike)

From the above results, subject to the condition of no model deformation, the wave pressure when superposing the shaking and overflow is lower than the case of the shaking alone, while the hydrodynamic pressure differs in the structure with the vertical part. Conversely, in the structure with the sloping part, no difference in hydrodynamic pressure due to differences in the water level was observed. Also, behind the model, depending on the state of falling water of the overflowing water mass behind the model, the influence at superimposition is smaller due to the influence of the overflow on the upper side of the model, but higher on the lower side of the model.

\section{Difference in wave force acting on structures during excitation in the presence or absence of an overflow in the fixed experiment}

The variation of the influence of wave force on both the front and rear of the model was studied, based on the wave force acting on structures of different shapes.

As for the breakwater of the vertical-caisson type, since both the front and rear of the model are vertical, the overall wave force when superposing shaking and overflow is about 1.1 times higher at the front of the model than where only the overflow acts, and about 0.9 times on the model rear.

In the sloping top-caisson type, with a slope structure on the upper side of the model, the wave force when superposing the shaking and overflow was about 1.05 times at the front of the model and about 0.9 times at the rear of the model, compared with the case where the overflow alone acted. This is because the dynamic force due to the shaking was suppressed at the slope of the model front, while the wave force declined at the front of the model, and the rear of the model was vertical and hence showed the same tendency as the breakwater of the vertical-caisson type.

In the coastal dike-type structure, the wave force when superposing the shaking and overflow was about 1.0 times larger at the model front than in the case where only the overflow acted and about 1.0 times at the rear of the model. This is thought to be due to having a slope structure on both the front and rear sides of the model, making it more resilient to hydrodynamic pressure at the time of shaking and meaning structural impact was unlikely to occur.

Based on the results of this experiment, it can be confirmed that the hydrodynamic pressure on that part is limited in a structure with a sloping part, even within the structure and the wave force acting on the structure when superposing the shaking and overflow can be reduced. However, in this study, since the structure is implemented under the condition that the structure does not deform, any structural deformation considered must be separately examined. (Fig. 5) 


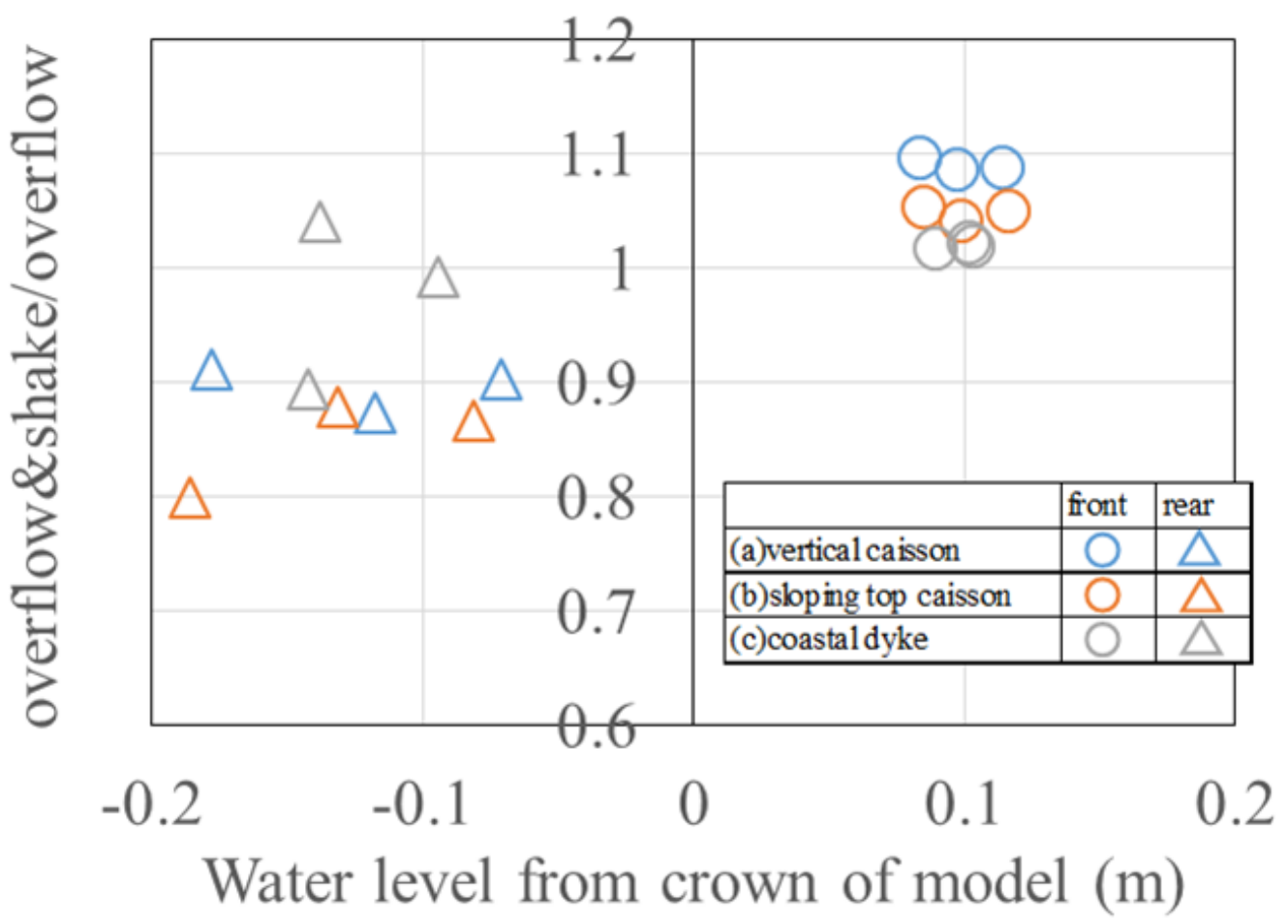

Figure 5 Relationship between water level difference and wave force

\section{Varying influence due to the difference in shape when superposing an earthquake and tsunami in a non-fixed experiment}

To confirm the influence of structural acceleration that cannot be determined by a fixed experiment, a non-fixed experiment was performed. Two such non-fixed experiments were performed, on breakwaters of the vertical-caisson and sloping top-caisson types respectively.

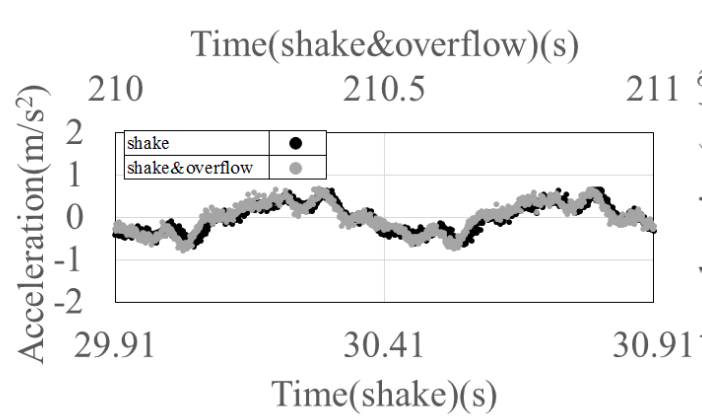

(a)Mound

Time(shake\&overflow)(s)

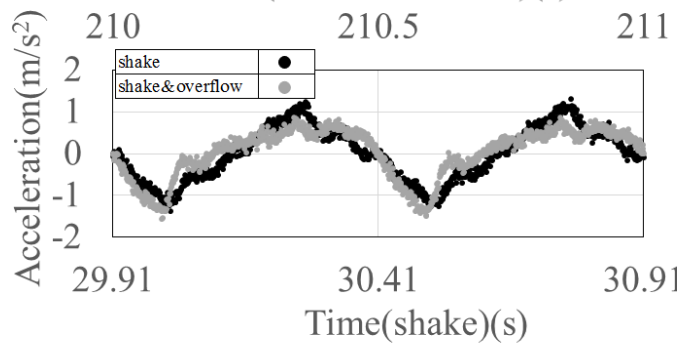

(c) Model Upper side

Difference in water level $0.22 \mathrm{~m}$
Time(shake\&overflow)(s)

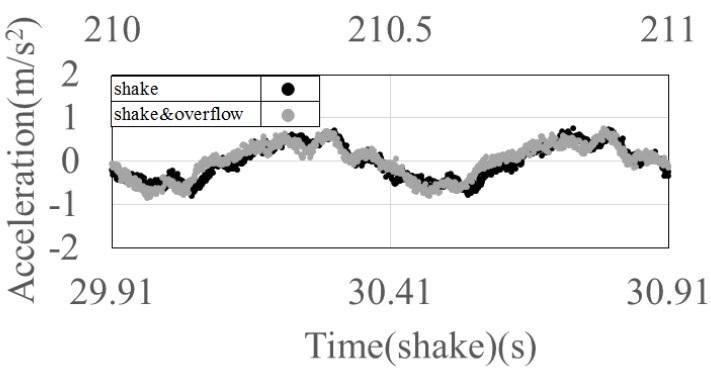

(b) Model lower side

Time(shake\&overflow)(s)

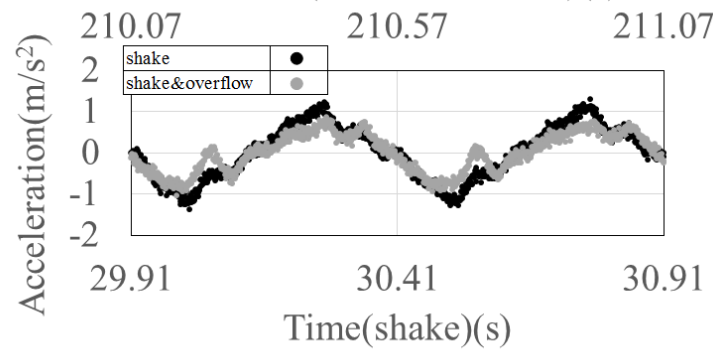

(d) Model Upper side

Difference in water level $0.13 \mathrm{~m}$

Figure 6 Vertical-caisson type acceleration time history 
For the acceleration, cases of shaking only and those superposing shaking and overflow were compared. For a breakwater of the vertical-caisson type, the accelerometers in the mound and lower model recorded $0.5 \mathrm{~m} / \mathrm{s}^{2}$. Conversely, acceleration on the upper side of the model increased to $1.0 \mathrm{~m} /$ $\mathrm{s}^{2}$ by shaking alone, but in the case where shaking and overflow were superimposed at a water level difference of $0.13 \mathrm{~m}$, the acceleration was about $0.8 \mathrm{~m} / \mathrm{s}^{2}$, while the water level difference where shaking and overflow were superposed at $0.22 \mathrm{~m}$ was found to be suppressed to about $0.5 \mathrm{~m} / \mathrm{s}^{2}$. (Fig. 6)

Likewise, in the sloping top-caisson type, which was shaken at 50 gal, the breakthrough with the vertical-caisson type inside the mound was $0.5 \mathrm{~m} / \mathrm{s}^{2}$ in the mound and under the model. Conversely, the acceleration on the upper side of the model increased to $1.0 \mathrm{~m} / \mathrm{s}^{2}$ by shaking alone, but when superposing shaking and overflow at a water level difference of $0.10 \mathrm{~m}$, it was almost the same as when shaking alone. However, in the case where shaking and overflow were superposed at a water level difference of $0.23 \mathrm{~m}$, it was found to be suppressed to about $0.5 \mathrm{~m} / \mathrm{s}^{2}$. (Fig. 7)

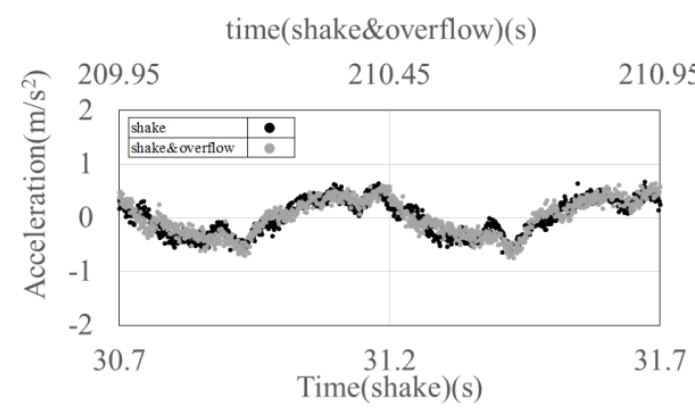

(a) Mound

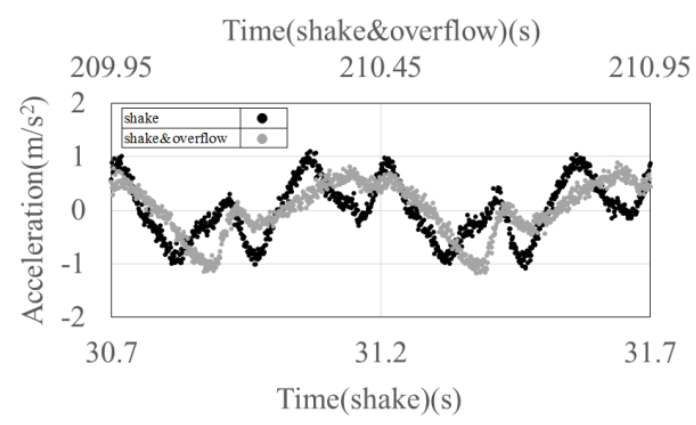

(c) Model upper side

difference in water level $0.23 \mathrm{~m}$

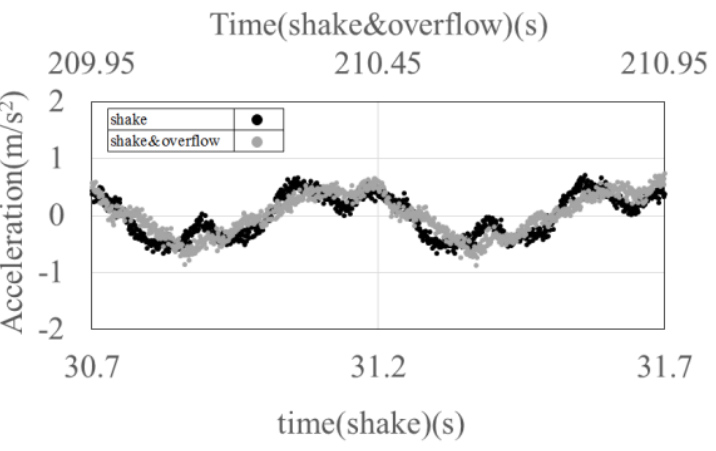

(b) Model lower side

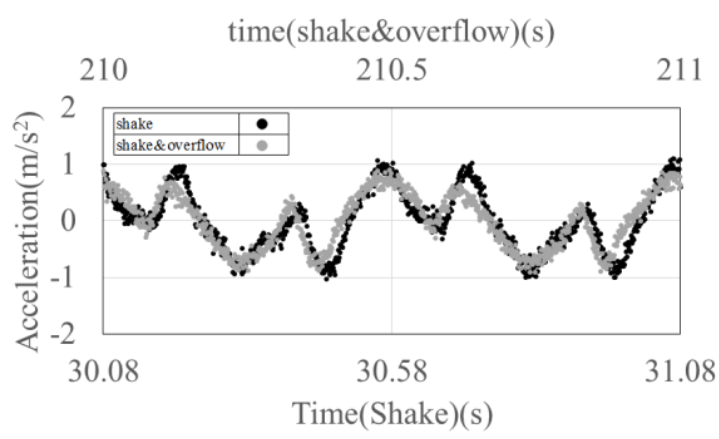

(d) Model upper side

difference in water level $0.10 \mathrm{~m}$

Figure 7 Sloping top-caisson type acceleration time history

\section{Study on breakwater stability during the earthquake and tsunami superposition in a non-fixed experiment}

The stability of the breakwater was examined using the result of wave pressure measured by a nonfixed experiment. In the study, the minimum safety factor when superposing the overflow and excitation was compared with the overflow condition before excitation. For the safety factor against sliding, data of the wave pressure gauge at both the front and rear of the model were used to calculate the sliding force, while the data of the accelerometers installed on the upper and lower sides of the model were averaged to obtain the inertial force. The frictional resistance with the mound due to the weight of the model was obtained as resistance force. Regarding the safety factor against overturning, the data of the wave pressure gauge attached around the model was defined as an overturning moment due to the wave force and the model weight was taken as resistance to the overturning moment. The calculation of the overturning moment due to the inertial force was obtained identically to the safety factor against sliding and the fulcrum of the moment was set behind the bottom of the model.

In both cases, the safety factor decreased before and after the shaking, but did not go below 1.0. The ratio of the safety factor before and after shaking was also taken and compared. In both cases, the safety factor against overturning was about 0.9 times that of the case with shaking and overflow and the overflow alone, irrespective of any difference in water level. For breakwaters of the vertical-caisson 
type, the safety factor against sliding was about 0.71 times when the water level difference was $0.14 \mathrm{~m}$, and about 0.81 times when the water level difference was $0.27 \mathrm{~m}$. Conversely, the breakwater for the sloping top-caisson type was about 0.70 times when the water level difference was $0.10 \mathrm{~m}$, but about 0.83 times when the water level difference was $0.23 \mathrm{~m}$.

In this study, despite not confirming differences in stability due to shape, in both cases, based on the water level difference increasing for the overflow alone and the difference in the safety factor against sliding when shaking and overflow were combined, the diminishing trend could be determined. This is because the acceleration exerted on the model is suppressed and the influence of the hydrodynamic pressure and inertia force is reduced by the increase in the water level difference.

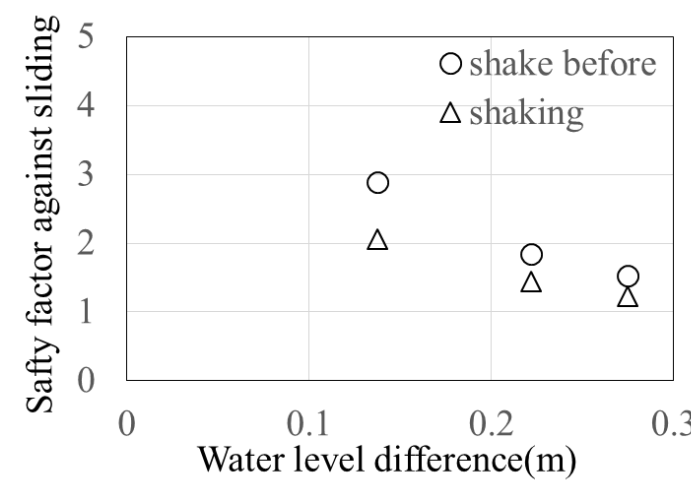

(a) Vertical caisson

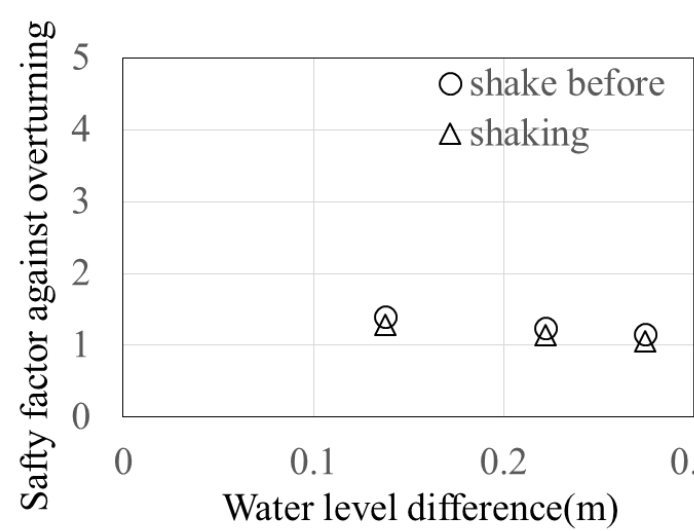

(a) Vertical caisson

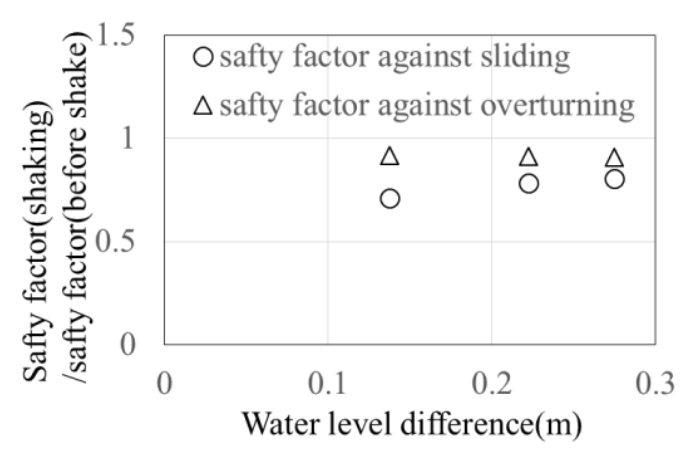

(a) Vertical caisson

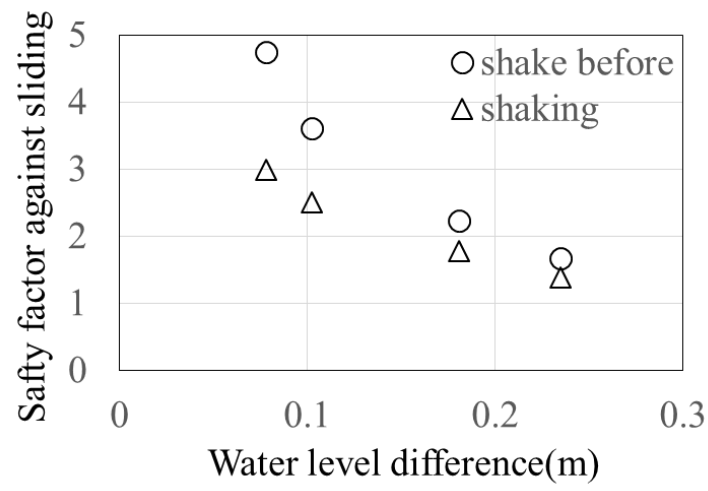

(b) Sloping top caisson

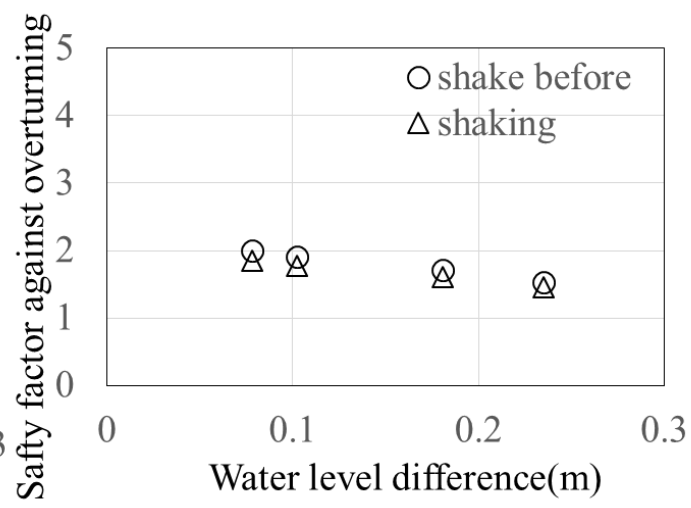

(b) Sloping top caisson

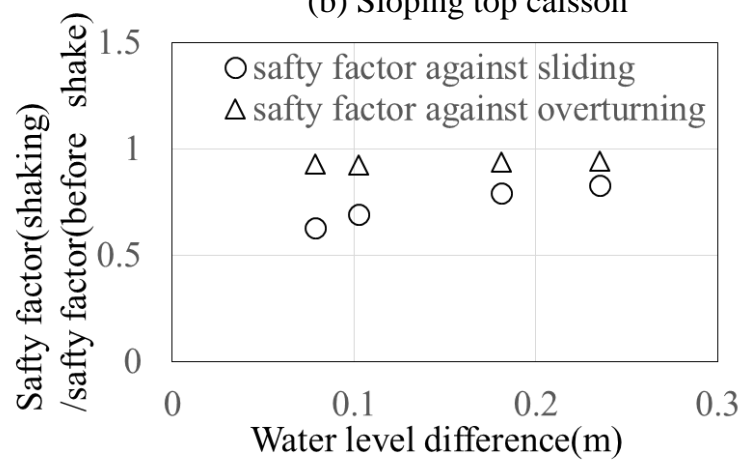

(b) Sloping top caisson

Figure 8 Relationship between water level difference and safety factor 


\section{CONCLUSION}

In this study, the following results were obtained.

Differing breakwater shapes meant hydrodynamic pressure increased for structures with a vertical part when the effects of an earthquake and tsunami were superposed. For structures with a sloping part, however, the influence of hydrodynamic pressure when superposing the earthquake and tsunami was difficult to determine.

For the wave force, when superposing the earthquake and tsunami due to the different shape of the breakwater, it became clear that the wave force when overlapping could be suppressed by reducing the hydrodynamic pressure at the slope.

Regarding the breakwater stability, it was revealed that the acceleration when superposing the earthquake and tsunami declined and the impact of inertial force and dynamic pressure decreased, regardless of differences in shape, as the water level difference increased.

\section{REFERENCES}

Arikawa, Sato; Shimosako, Hasegawa, Yeom, Tomita. (2012),

"Failure Mechanism of Kamaishi Breakwaters due to the Great East Japan Earthquake Tsunami," International Conference on Coastal Engineering (ICCE) Proceedings 2012, COPRI, ASCE

Arikawa, Sato, Shimosako, Tomita, Yeom and Niwa, (2013),

"Failure Mechanism and Resiliency of Breakwaters under Tsunami,"

Technical Note of Port and Airport Research Institute, No. 1269. 